\title{
ELECCIONES GENERALES CONVOCADAS POR REAL DECRETO 794/1986, DE 22 DE ABRIL
}

\author{
POR \\ ENRIQUE ARNALDO ALCUBILLA \\ Letrado de las Cortes Generales
}

El objeto de la Crónica Electoral es recoger ordenada y sistematizadamente los acuerdos, resoluciones e instrucciones del órgano que ocupa el lugar preeminente dentro de la Administración Electoral, la Junta Electoral Central. A este órgano le corresponde fijar los criterios esenciales para una interpretación auténtica de la legislación electoral.

En esta Crónica seguiremos el mismo método que en la anterior ${ }^{1}$, agrupando tales acuerdos, resoluciones e instrucciones por materias, siguiendo los enunciados de la LOREG e incorporando un primer epígrafe sobre la normativa básica en la consulta electoral objeto de consideración, en este caso las elecciones convocadas por Real Decreto 794/1986, de 22 de abril. Se añade un Anexo en el que se incluyen los acuerdos y resoluciones de la JEC en relación con las elecciones al Parlamento de Andalucía convocadas por Decreto del Presidente de la Junta de Andalucía 73/1986, de 28 de abril.

1 Véase E. Arnaldo Alcubilla, "Crónica Electoral. Referéndum convocado por Real Decreto 214/1986, de 6 de febrero, sobre la incorporación de España a la Alianza Atlántica". Revista de las Cortes Generales, núm. 8 págs. 343-370. 
I. NORMATIVA BASICA SOBRE ELECCIONES GENERALES: EN PARTICULAR LAS ELECCIONES AL CONGRESO DE LOS DIPUTADOS Y AL SENADO CONVOCADAS POR R.D. 794/1986, DE 22 DE ABRIL 19 de junio.

— Ley Orgánica del Régimen Electoral General, L.O. 5/1985, de

- R.D. 1732/1985, de 24 de septiembre, por el que se regulan las condiciones de los locales y las características oficiales de los elementos materiales a utilizar en los procesos electorales.

- R.D. 1733/1985, de 24 de septiembre, sobre solicitud del voto por correo en casos de enfermedad o incapacidad que impida formularla personalmente y por la restante normativa de desarrollo.

- R.D. 803/1986, de 25 de abril, por el que se dictan normas para la celebración de las elecciones de 22 de junio de 1986.

- ORDEN de 25 de abril de 1986, por la que se fijan las cantidades actualizadas de las subvenciones a los gastos originados por actividades electorales para las elecciones generales de 22 de junio de 1986.

- ORDEN de 30 de abril de 1986, por la que se dictan normas en relación con el franqueo y depósito en el Servicio de Correos de los envíos de propaganda electoral en las elecciones al Congreso de los Diputados y al Senado.

- ORDEN de 5 de mayo de 1986, por la que se dictan normas sobre la colaboración del Servicio de Correos en las elecciones al Congreso de los Diputados y al Senado. Convocadas por R.D. 794/1986, de 22 de abril. Corrección de errores publicada en BOE núm. 127 de 28 de mayo.

- ORDEN de 5 de mayo de 1986, por la que se dictan normas en relación con el franqueo y depósito en el Servicio de Correos de los envíos de propaganda electoral para las elecciones al Congreso de los Diputados y al Senado. Convocadas por R.D. 794/1986, de 22 de abril.

- ORDEN de 12 de mayo de 1986, sobre características de las papeletas y sobres a utilizar en la votación al Senado en las Elecciones Generales.

- R.D. 1194/1986, de 6 de junio, por el que se concede franqui- 
cia telegráfica para los radiotelegramas, barco-tierra originados por los navegantes con motivo de las Elecciones a Cortes Generales de 1986. Convocadas por R.D. 794/1986, de 22 de abril.

- ACUERDO de 23 de mayo de 1986 del Pleno del Tribunal Constitucional, por el que se aprueban normas sobre tramitación del recurso de amparo previsto en el art. 49.3 y 4 de la Ley Orgánica 5/1985, de 19 de junio, del Régimen Electoral General.

II. INSTRUCCIONES, ACUERDOS Y RESOLUCIONES DE LA JUNTA ELECTORAL CENTRAL

\section{Derecho de sufragio pasivo. Inelegibilidad e incompatibilidad}

- Consulta sobre posible inelegibilidad o incompatibilidad de Alcaldes y Presidentes de Diputación (Acuerdo de 5 de mayo de 1986).

La Junta acuerda que, con arreglo a la Ley, no concurre causa de inelegibilidad o incompatibilidad en los Alcaldes y Presidentes de Diputación.

- Consulta sobre inelegibilidad de los representantes de las Comisiones Mixtas de Transferencias y Valoraciones nombrados por las Comunidades Autónomas (Acuerdo de 12 de mayo de 1986).

La Junta acuerda que no concurre causa de inelegibilidad en los Vocales de las Comisiones Mixtas designadas por los Consejos de Gobierno de las Comunidades Autónomas.

- Consulta sobre posible inelegibilidad de los representantes de la Generalitat en el Consorcio de Promoción Turística de Catalunya (Acuerdo de 12 de mayo de 1986).

La Junta acuerda que debe entenderse comprendidos a los citados representantes en la inelegibilidad para el Congreso de los Diputados prevista en el art. 154.2 de la Ley Electoral, por cuanto, de conformidad con el Decreto de la Generalitat 13/1986, de 16 de enero, por el que se constituye el Consorcio, éste es un ente permanente dotado de personalidad jurídica pública, independientemente de que formen parte de sus órganos de gobierno determinadas representaciones sociales; pero los representantes oficiales designados por la Generalitat lo son por Decreto del Presidente de la misma, acordado en Consejo Ejecutivo de la citada 
Generalitat, con el carácter de cargos públicos a que alude el citado precepto de la Ley Orgánica Electoral.

- Consulta sobre posible inelegibilidad de los Delegados Territoriales de los Entes Autonómicos (Acuerdo de 12 de mayo de 1986).

La Junta acuerda que, de conformidad con el art. 154.2 de la Ley Electoral, serán inelegibles en el caso de que su designación corresponda libremente al Consejo de Gobierno, pero no si tal designación corresponde a los Consejeros Autonómicos; en el primer caso, por analogía con lo dispuesto en el art. $6 .^{\circ} 3$. a) debe entenderse la inelegibilidad como relativa, esto es, limitada al ámbito territorial en que ejerzan su función.

- Consulta sobre elegibilidad de un Presidente del Parlamento Autonómico (Acuerdo de 12 de mayo de 1986).

La Junta acuerda que no concurre causa de inelegibilidad para el Congreso de los Diputados en el Presidente del Parlamento Autonómico, por cuanto la inelegibilidad del último inciso del art. 154.2 se refiere a «los miembros de las instituciones autonómicas que por mandato estatutario o legal deban ser elegidos por la Asamblea legislativa correspondiente", lo que debe entenderse referido a instituciones distintas de la propia Asamblea legislativa, tales como pueden ser los órganos equivalentes al Defensor del Pueblo o a los órganos de Administración de la televisión autonómica u otros supuestos similares, pero no a un órgano propio interno de la misma Asamblea legislativa.

- Consulta sobre inelegibilidad de quienes están cumpliendo el servicio militar (Acuerdo de 19 de mayo de 1986).

La Junta acuerda que no concurre inelegibilidad en los soldados que se encuentren cumpliendo el servicio militar, puesto que la Ley Electoral contempla solamente la inelegibilidad de los militares profesionales y de complemento.

\section{Administración electoral. Juntas Electorales}

28 de abril de 1986).

La Junta, enterada del acuerdo de la Comisión Permanente del Consejo General del Poder Judicial acerca de los Vocales de origen judicial de las Juntas Provinciales y de Zona, acuerda comunicar a las Juntas Electorales Provinciales que deberá procederse en su momento, conforme a lo previsto en la Ley Orgánica del Régimen Electoral General, 
a la designación de los Vocales contemplados en las letras b) de los artículos 10.1 y 11.1 de la citada Ley, sin perjuicio de que, en las cuestiones que aún se susciten en relación con el Referéndum celebrado el 12 de marzo de 1986, sigan funcionando las Juntas Provinciales y de Zona constituidas en orden al citado Referéndum.

En el mismo punto, ante diversas consultas sobre traslados de Vocales de origen judicial de las Juntas Electorales Provinciales y de Zona, la Junta acuerda comunicar que el traslado debe considerarse causa justificada de renuncia a la condición de miembro de la Junta, procediéndose, por tanto, a la sustitución, conforme a lo dispuesto en el artículo 17 de la Ley Electoral.

Finalmente, se acuerda que, una vez designados con arreglo a la Ley los Vocales de origen judicial de las Juntas Electorales Provinciales y de Zona, no cabe alterar la composición de éstas por el hecho de que haya sido nombrado un juez o magistrado en la provincia o en el partido judicial correspondiente y, que en el momento de la designación pudiera tener mejor derecho a ella.

- Solicitud de un Ayuntamiento de que se constituya Junta de Zona en el nuevo Partido Judicial creado (Acuerdo de 28 de abril de 1986).

La Junta acuerda que, con arreglo al art. 8.6 de la Ley Electoral, a los efectos de dicha Ley, los Partidos Judiciales coinciden con los de las elecciones locales de 1979, lo que impide la constitución de una nueva Junta de Zona.

- Consulta sobre si debe cesar como Vocal de la Junta Electoral Provincial un magistrado que va a pasar a formar parte de la Sala de lo Contencioso-Administrativo (Acuerdo de 28 de abril de 1986).

La Junta acuerda que el supuesto citado no implica el cese en la condición de miembro de la Junta, sin perjuicio de que, en su caso, el magistrado vocal de la Junta pudiese estar afectado por causa de abstención en relación con posibles recursos contenciosos-electorales.

- Comunicación de determinadas Juntas Electorales Provinciales y de Zona en el sentido de que consideran que los Vocales no judiciales elegidos a propuesta de los Partidos Políticos deben seguir formando parte de las mismas (acuerdo de 12 de mayo de 1986).

La Junta acuerda mantener y reiterar su acuerdo en el sentido de que en el momento correspondiente del calendario electoral deberá procederse a la designación de los Vocales previstos en las letras b) de los artículos 10.1 y 11.1 de la Ley Electoral. En este sentido, se acuerda dirigir a todas las Juntas Provinciales circular para que remitan a la Junta 
Electoral Central en su momento las propuestas recibidas y, en su defecto, se formule propuesta por las propias Juntas Provinciales.

- Solicitud de la Junta Electoral de Zona de Ceuta de que, ante las competencias que tiene acumuladas, sea considerada a todos los efectos como Junta Electoral Provincial (Acuerdo de 12 de mayo de 1986).

La Junta acuerda transmitir el escrito de la Junta de Zona de Ceuta al Ministerio del Interior, exponiendo el criterio de la Junta favorable a la pretensión articulada, por cuanto, con arreglo al artículo 8 de la Ley Electoral, las Juntas de Ceuta y Melilla acumulan las funciones de la Provincial y de Zona.

- Consulta de una Junta Electoral Provincial sobre cómo completar la composición de una Junta Electoral de Zona cuando sólo existe un Licenciado en Derecho en todo su ámbito (Acuerdo de 26 de mayo de 1986).

La Junta acuerda que, siendo taxativa la exigencia de la condición de Licenciado en Derecho, no podrá cubrirse la segunda vocalía de la Junta de la Zona.

- Consulta sobre composición de una Junta de Zona una vez que cesa el Presidente como Magistrado Juez de Primera Instancia e Instrucción para pasar a la Audiencia Provincial (Acuerdo de 2 de junio de 1986).

La Junta acuerda que deberá comunicarse la vacante a la Sala de Gobierno correspondiente para que proceda al sorteo previsto en la Ley.

- Comunicación de una Junta Electoral Provincial sobre la conveniencia de nombrar Vicepresidentes en las Juntas Electorales Provinciales y Juntas de Zona, pese a no estar consignando el nombramiento en la Ley Electoral (Acuerdo de 2 de junio de 1986).

La Junta acuerda que, no estando prevista la Vicepresidencia en la Ley Electoral, deberán aplicarse las normas de la Ley de Procedimiento Administrativo sobre órganos colegiados.

- Recurso contra acuerdo de una Junta Electoral Provincial relativo a nombramiento de Vocales no judiciales de la Junta de Zona de dicha circunscripción (Resolución de 2 de junio de 1986).

La Junta acuerda desestimar el recurso por cuanto la Provincial ha aplicado correctamente el criterio, ya sentado por esta Junta, de que, dada la distinta indole de la normativa aplicable a la consulta del referén- 
dum y a las presentes elecciones generales no cabía prorrogar el mandato de los Vocales previstos en el art. 10.1. b) de la Ley Electoral.

- Acuerdo de 2 de junio de 1986 de la JEC por el que se designa a los Vocales de las Juntas Electorales Provinciales previstos en el art. 10.1.b) de la LOREG ${ }^{2}$.

- Recurso contra acuerdo de la Junta Electoral Central sobre designación de Vocales de una Junta Electoral Provincial (Resolución de 9 de junio de 1986).

La Junta desestima el recurso de conformidad con su criterio ya reiteradamente sentado, en el sentido de que no procede entender prorrogado para las presentes elecciones el mandato de los Vocales previstos en las letras b) de los arts. 10.1 y 11.1 de la Ley Electoral que fueron designados en su día para el referéndum convocado por Real Decreto 214/1986, de 6 de febrero.

- Recurso de un partido político contra la designación de los Vocales no judiciales en determinada Junta Electoral Provincial y de Zona (Resolución de 9 de junio de 1986).

La Junta acuerda desestimar el recurso por cuanto, con arreglo a los arts. 10.1.b) y 11.1. b) de la Ley Electoral, las propuestas aludidas en dichos preceptos han de ser conjuntas por las entidades políticas con derecho a formularlas.

\section{Administración Electoral. Mesas y Secciones Electorales}

- Consulta de determinadas Juntas Electorales Provinciales sobre si han de constituirse nuevas Mesas Electorales (Acuerdo de 28 de abril de 1986).

La Junta acuerda comunicar a las dos consultantes que ha de procederse a la designación de nuevas Mesas Electorales pues ningún precepto autoriza a prorrogar el mandato de las constituidas en orden al referéndum ni impone dicha carga más allá de lo relativo a cada consulta electoral en particular.

- Consulta sobre designación de Mesas Electorales (Acuerdo de 5 de mayo de 1986).

La Junta acuerda que, dado que el art. 26 de la Ley Electoral en-

2 Véase BOE núm. 113, de 4 de junio de 1986. 
comienda la formación de las Mesas a los Ayuntamientos bajo la supervisión de las Juntas Electorales de Zona, no resulta posible que la designación se haga por el Alcalde o miembro de la Corporación en quien delegue.

- Consulta de un Ayuntamiento sobre competencia para notificar a los interesados la designación de miembro de las Mesas Electorales. (Acuerdo de 26 de mayo de 1986).

La Junta acuerda que, siendo el Ayuntamiento el órgano competente para la designación, él mismo debe notificarlo ${ }^{3}$.

- Solicitud de un Ayuntamiento de constitución de Mesa Electoral en determinado ente local (Acuerdo de 2 de junio de 1986).

La Junta acuerda dar traslado de dicha solicitud a la Oficina del Censo Electoral.

- Consulta sobre si corresponde al Ayuntamiento o a la Junta Electoral de Zona la designación de los miembros titulares y suplentes de las Mesas Electorales en sustitución de los inicialmente nombrados (Acuerdo de 18 de junio de 1986).

La Junta acuerda que, de conformidad con lo previsto en el art. 26.1 de la Ley Orgánica del Régimen Electoral General, tal designación corresponde a los Ayuntamientos, bajo la supervisión de las Juntas de Zona, a través del procedimiento previsto en el párrafo $2 .^{\circ}$

- Consulta sobre la designación de militares profesionales y de complemento como componentes de las Mesas Electorales (Acuerdo de 22 de septiembre de 1986).

La Junta acuerda que, de conformidad con el art. $6 .^{\circ}-1$. i) son ineligibles alos militares profesionales y de complemento y los miembros de las Fuerzas y Cuerpos de Seguridad y Policía en activo"; por lo que, conforme con el inciso final del art. 27.2 ha de considerarse causa justificada para no aceptar la condición de miembro de mesa el ser militar en activo.

\section{Censo Electoral}

- Consulta sobre posibilidad de utilización del Padrón municipal de habitantes en lugar de las listas del Censo electoral (Acuerdo de 19 de mayo de 1986).

3 En el mismo sentido Acuerdo de 9 de junio de 1986 
La Junta acuerda que, a efectos de la designación de los miembros de las Mesas Electorales, ha de utilizarse el Censo electoral, cuya lista ha de ser puesta a disposición de los Ayuntamientos.

- Solicitud de una Junta Electoral Provincial de disponer de un ejemplar del Censo electoral (Acuerdo de 19 de mayo de 1986).

La Junta acuerda mantener sus anteriores acuerdos en el sentido de que no existe la necesidad de que las Juntas Provinciales dispongan de las listas del Censo electoral, sin perjuicio de que, en la medida en que pudieran dichas Juntas necesitar el conocimiento de datos relativos al Censo puedan requerir el auxilio de las Delegaciones Provinciales de la Oficina del Censo Electoral.

- Escrito de una Junta Electoral Provincial en el que se interesa se ponga a su disposición un ejemplar del Censo electoral de esa circunscripción (Acuerdo de 2 de junio de 1986).

La Junta acuerda comunicar a la Provincial que, en la medida en que para el ejercicio de sus funciones pueda necesitar la utilización de un ejemplar del Censo electoral, debe requerir el concurso de la Oficina del Censo Electorál ${ }^{4}$.

\section{Procedimiento electoral}

\section{Representantes ante la Administración Electoral}

- Escrito de una coalición electoral solicitando a la Junta Electoral Central comunique a las Juntas Provinciales que los representantes de candidaturas pueden hacer uso de todas las facultades previstas en la LOREG, sin necesidad de poder especial (Acuerdo de 19 de mayo de 1986).

La Junta acuerda comunicar a todas las Provinciales que los representantes de candidaturas de la citada coalición tienen las facultades legales previstas en la Ley Electoral, la cual les habilita para realizar válidamente todos los actos correspondientes salvo en la medida que en el trámite de plazo de subsanación de candidatura se presenten candidatos nuevos, a cuyo efecto habrá que estar a la habilitación mediante poder especial según tiene acordado la mencionada coalición y comunicado a esta Junta con solicitud de traslado a todas las Juntas Provinciales.

4 En el mismo sentido Acuerdo de 18 de junio de 1986. 
- Reclamación de un partido político contra designación de representantes por otro partido político (Resolución de 26 de mayo de 1986).

La Junta acuerda desestimar dicha reclamación, por cuanto el partido político contra el que se dirige la reclamación está inscrito con tal denominación en el Registro de Partidos Políticos, por lo que tiene derecho a la utilización de la misma ${ }^{5}$.

\section{Presentación y proclamación de candidaturas *}

- Acuerdo de 5 de mayo de 1986 sobre publicación de las candidaturas presentadas y de las proclamadas dentro de los plazos legales.

La Junta acuerda instruir a las Provinciales para que, en orden a garantizar la publicación en los términos legales de las candidaturas presentadas y, en su momento, de las proclamadas, se actúe de la siguiente forma:

1. Las Juntas Electorales Provinciales harán llegar, a partir de las cero horas del día 14 de mayo próximo, a los Gobiernos Civiles respectivos, copia certificada de las candidaturas presentadas. Dicha copia del acta de la Junta Electoral Provincial, se cuidará que sea un original o copia perfectamente legible y que las hojas vayan numeradas.

2. Del mismo modo, el día 20 de mayo entregarán a los Gobiernos Civiles las candidaturas proclamadas en cada provincia, con formato, requisitos y características idénticas a las señalas en el punto anterior.

3. Cada uno de los Gobiernos Civiles transmitirá vía DEX a la Dirección General de Política Interior, el día correspondiente, las copias certificadas de las actas referidas a las candidaturas presentadas y las candidaturas proclamadas.

5 La reclamación se fundaba en la similitud de siglas entre ambas entidades políticas.

* Véase:

- BOE núm. 116. Candidaturas presentadas para las elecciones al Congreso de los Diputados y al Senado convocadas por R.D. 794/86, de 22 de abril.

- BOE núm. 121. Candidaturas proclamadas para las elecciones al Congreso de los Diputados y al Senado convocadas por R.D. $794 / 86$ de 22 de abril.

- BOE núm. 126, 127, 128, 132 y 135. Corrección de errores de la relación de las candidaturas proclamadas para las elecciones del Congreso de los Diputados y el Senado insertas en suplemento al BOE núm. 121, de 21 de mayo. 
4. La Dirección General de Política Interior hará llegar a los senvicios del Boletín Oficial del Estado las citadas copias para su publicación en las fechas previstas en la Ley.

5. Las candidaturas presentadas tendrán que obrar en poder de la Dirección General de Política Interior, recibidas a través de los Gobiernos Civiles, antes de las 10 horas del día 14 de mayo, y las que se refieren a candidaturas proclamadas, antes de las 11 horas del día 21 de mayo.

- Consulta de una coalición electoral sobre obligación de expresar en las candidaturas presentadas ante las Juntas Provinciales el símbolo y siglas de la coalición (Acuerdo de 5 de mayo de 1986).

La Junta acuerda que, una vez hechos constar el símbolo y siglas ante esta Junta Electoral Central en el acto de constitución de la coalición electoral, la designación ante las Juntas Provinciales del símbolo y siglas que constan en la constitución de la coalición, debe considerarse expresión clara de dichos elementos identificadores a los efectos previstos en el art. 46.9 de la Ley Electoral.

- Consulta sobre cuál es la Junta Electoral competente para constitución de coaliciones (Acuerdo 5 de mayo de 1986).

La Junta acuerda que si el ámbito de la coalición comprende más de una provincia, la Junta Electoral competente para hacer constar su constitución es la Junta Electoral Central, en caso de que la coalición se circunscriba a una sola provincia cabe hacer constar su constitución tanto ante la Junta Electoral Central como ante la Provincial.

- Consulta sobre número de candidatos que una entidad política pueda presentar en las elecciones para el Senado (Acuerdo de 5 de mayo de 1986).

La Junta acuerda dirigir circular a todas las Juntas Provinciales en el sentido de que cada entidad política puede presentar en cada distrito electoral tantos candidatos al Senado, cada uno con su suplente, como escaños de Senadores haya de cubrirse por el correspondiente distrito electoral, sin perjuicio de que, con arreglo a lo dispuesto en el art. 166.1. a), los electores pueden dar su voto a un máximo de tres candidatos en las circunscripciones provinciales, dos en Gran Canaria, Mallorca, Tenerife, Ceuta y Melilla y uno en las restantes circunscripciones insulares.

- Consulta de una entidad política sobre si se pueden presentar las candidaturas a través del Gobierno Civil (Acuerdo de 12 de mayo de 1986).

La Junta acuerda que en este punto no cabe considerar supletorio 
el art. 66 de la Ley de Procedimiento Administrativo, por lo que las candidaturas deben presentarse directamente en las propias Juntas Provinciales.

- Reclamación de una asociación civil contra la constitución de una coalición electoral cuya denominación es similar a la de aquélla (Acuerdo de 12 de mayo de 1986).

La Junta acuerda desestimar la reclamación de la citada asociación civil en consideración a los distintos fines de una asociación civil y de una coalición electoral y, teniendo en cuenta, además, que la identificación de una Coalición electoral como la de cualquier otra entidad política es el resultado de una serie de elementos, como son la denominación, emblema, siglas, anagrama, símbolos, etc.

- Consulta sobre candidaturas al Senado sin suplentes (Acuerdo de 19 de mayo de 1986).

La Junta acuerda que en el plazo legal de subsanación puede procederse a la inclusión de los suplentes pero, en todo caso, a falta de subsanación, la omisión de suplentes en las candidaturas del Senado no impide la proclamación de tales candidaturas, sin perjuicio de que, en caso de que resultara elegido Senador uno de estos candidatos sin suplente, la vacante que eventualmente pudiera producirse no podría ser cubierta.

- Consulta sobre posibilidad de sustitución de un candidato al Senado, que renuncie a la candidatura, por una persona que no figuraba como suplente en la candidatura inicial presentada (Acuerdo de 19 de mayo de 1986).

La Junta acuerda que el art. 48.1 de la Ley Electoral permite la modificación de las candidaturas en el plazo para subsanación, entre otros supuestos, por renuncia del Titular, lo que abre la posibilidad de que, en tal trámite de subsanación y en el supuesto aludido, se designe nuevo candidato titular en lugar del renunciante, dado que, además, el art. 48.2 sólo prevé como obligatoria la sustitución por el suplente después de la proclamación y cuando se trate de listas de candidatos, supuesto este último que no concurre a las elecciones al Senado.

- Reclamación de un partido político contra la utilización por otro partido político de determinadas siglas que pudieran inducir a confusión con la denominación del partido político reclamante (Resolución de 19 de mayo de 1986).

La Junta acuerda desestimar la reclamación, por cuanto, por una parte, el partido político contra el que se formula la reclamación tiene inscrito en el Registro de Partidos Políticos como formando parte de su denominación las iniciales citadas; además, la identificación de las distintas 
entidades políticas es resultado del conjunto formado por la denominación, siglas, símbolos, emblema, etc., conjunto que evita la confusión aducida por el reclamante.

- Consulta sobre el plazo de subsanación de irregularidades en la presentación de candidaturas (Acuerdo de 19 de mayo de 1986).

La Junta acuerda que el cómputo del citado plazo debe entenderse que comienza a las cero horas del día 18 de mayo, por lo que el plazo de 48 horas para la subsanación concluye a las 24 horas del día $19^{6}$.

- Recurso de una entidad política contra acuerdo de la Junta Electoral Provincial que exige la comparecencia personal de los candidatos para ratificar la declaración de aceptación de la candidatura (Resolución de 19 de mayo de 1986).

La Junta acuerda que basta con que los candidatos hayan firmado el escrito de aceptación de las candidaturas y certificación de inscripción en el Censo, junto con la fotocopia simple del DNI, sin que habiéndose cumplido estos requisitos sea necesaria la comparecencia personal de los candidatos ante la Junta.

- Recurso de una entidad política contra acuerdo de la JEP por el que se comunican irregularidades de candidaturas (Resolución de 26 de mayo de 1986).

La Junta acuerda que, tal como se deduce del informe de la Junta Provincial, procede declarar la inadmisión del recurso, puesto que el acto impugnado no es definitivo ni tampoco acto de trámite que determine la imposibilidad de continuar el procedimiento o produzca indefensión.

- Consulta sobre cambio del símbolo reconocido por un determinado partido político (Acuerdo de 26 de mayo de 1986).

La Junta acuerda que, una vez proclamadas las candidaturas, no cabe admitir alteración de los distintos elementos de las mismas entre los que se encuentra el símbolo.

- Solicitud del representante de una candidatura para que se requiera a una entidad política para retirar de sus candidaturas determinadas siglas (Acuerdo de 26 de mayo de 1986).

La Junta acuerda que la competencia en dicha materia en cuanto relativa a proclamación de candidatura corresponde a las Juntas Electorales Provinciales.

6 Véase art. 47.2 LOREG. 
- Reclamación sobre proclamación de su candidatura y exclusividad de uso de su denominación en virtud de sentencia en recurso sobre proclamación de candidaturas (Resolución de 2 de junio de 1986).

La Junta acuerda desestimar la reclamación, por cuanto la ejecución de tales sentencias corresponde a las Juntas Provinciales cuyos acuerdos de proclamación hayan sido objeto de impugnación en los términos que se desprende de la parte dispositiva de la sentencia.

- Consulta sobre consecuencia de la renuncia de un candidato al Senado proclamado sin suplente, habiéndose producido la renuncia después de la publicación de las candidaturas proclamadas (Acuerdo de 2 de junio de 1986).

La Junta acuerda que, dados los términos del art. 48 de la Ley Electoral, no cabe suplir al candidato renunciante, según tiene ya acordado esta Junta Electoral Central.

- Consulta sobre renuncia de un candidato al Senado proclamado sin suplente (Acuerdo de 9 de junio de 1986).

La Junta acuerda que si el candidato proclamado ha renunciado debe tenérsele por renunciado efectivamente y ser nulos los votos que se puedan emitir a su favor.

- Escrito de una entidad política solicitando aclaración sobre el alcance de la sentencia que le reconocía el derecho a presentar candidaturas en las elecciones generales convocadas (Acuerdo 9 de junio de 1986).

La Junta acuerda comunicar al solicitante que la competencia en la materia corresponde a las Juntas Provinciales cuyos acuerdos hayan sido anulados o modificados por sentencia dictada en los recursos contra la proclamación de candidaturas, así como a los propios órganos judiciales de los que proceda la sentencia.

- Recurso de un partido político contra acuerdo de la JEP denegatorio de la solicitud de inelegibilidad de un candidato de una coalición electoral (Resolución de 18 de junio de 1986).

La Junta acuerda declarar inadmisible el recurso, por cuanto, en materia que afecta a proclamación de candidaturas, no cabe recurso de alzada contra los acuerdos de las Juntas Provinciales.

- Consulta sobre forma de llevar a cabo la retirada de candidaturas en diversas provincias (Acuerdo de 18 de junio de 1986).

La Junta acuerda que la retirada de candidaturas debe efectuarse 
personalmente por el representante de la citada entidad política en cada circunscripción electoral.

\section{Propaganda y actos de campaña electoral}

Utilización de medios de comunicación de titularidad pública para la campaña electoral

- Acuerdo de 28 de abril de 1986 de la Junta Electoral Central, sobre delegación de las competencias previstas en el artículo 65.5 de la Ley Orgánica del Régimen Electoral General.

- Escrito de un partido político solicitando espacios gratuitos de campaña electoral (Acuerdo de 19 de mayo de 1986).

La Junta acuerda remitir en su momento el escrito a la Comisión de Radiotelévisión, a los efectos que estime oportunos, en orden a la propuesta de distribución de espacios que dicha Comisión ha de elevar a la Junta.

- Escrito de una coalición electoral en solicitud de espacios electorales y de representación en la Comisión de Radiotelevisión (Acuerdo de 19 de mayo de 1986).

En cuanto a la solicitud de espacios gratuitos de campaña electoral, la Junta acuerda dar traslado en su momento a la Comisión de Radiotelevisión, a los efectos que estime oportunos; por lo que se refiere a la solicitud de representación en la citada Comisión de Radiotelevisión, la Junta acuerda desestimar la solicitud por cuanto el artículo 65.3 de la Ley Electoral reconoce el derecho de representación en la citada Comisión a las entidades políticas que cuenten con representación en el Congreso de los Diputados, condición que no ostenta la entidad solicitante, puesto que el candidato que fue Diputado del Congreso lo era por un partido político distinto.

- Escrito de varios partidos políticos en solicitud de aplicación de los criterios del artículo 64 de la Ley Electoral a los espacios informativos no gratuitos que emita TVE (Acuerdo de 19 de mayo de 1986).

La Junta acuerda que, tratándose de espacios de información, de carácter no gratuito, el procedimiento atributivo de competencias a la Junta Electoral Central es el previsto, en desarrollo del artículo 66 de la LOREG, en la Instrucción publicada por la Junta Electoral Central en fecha 7 de noviembre de $1985^{7}$.

7 Instrucción de la Junta Electoral Central de 4 de noviembre de 1985, publicada en el $B O E$ núm. 267, de 7 de noviembre de 1985. 
- Consulta de varios partidos políticos sobre si la presentación de candidaturas sólo al Congreso o sólo al Senado es suficiente a los efectos de que se entiendan presentadas candidaturas en el porcentaje de circunscripciones a que alude el art. 64.2 de la Ley Electoral (Acuerdo de 5 de mayo de 1986).

La Junta acuerda que, dado que el citado precepto legal no exige la presentación simultánea de candidaturas a ambas Cámaras como exigía alguna disposición anterior, ha de entenderse que basta a los citados efectos con la presentación a una de estas Cámaras.

- Consulta de un partido político sobre derechos en orden a espacios gratuitos de campaña electoral de partidos que en las elecciones de 1982 concurrieron formando parte de una coalición y ahora lo hacen independientemente (Acuerdo de 26 de mayo de 1986).

La Junta acuerda comunicar al partido que efectúa la consulta su criterio de atribuir al mismo, a los distintos efectos electorales, los escaños y votos correspondientes acreditadamente obtenidos por candidatos de dicho partido presentados por la coalición de 1982.

- Consulta sobre composición de la Comisión Provincial de Radiotelevisión (Acuerdo de 26 de mayo de 1986).

La Junta acuerda comunicar a la Provincial de Teruel que la citada Comisión la componen representantes de los partidos que hayan obtenido representación en el Congreso de los Diputados a través de la circunscripción.

- Consulta sobre si Radiotelevisión tiene obligación de facilitar medios técnicos (cámaras, platós, técnicos, etc.) para grabar los espacios gratuitos de campaña electoral (Acuerdo de 26 de mayo de 1986).

La Junta acuerda comunicar al citado partido que la Ley Electoral no impone tal obligación a los medios de titularidad pública.

- Acuerdo de la Junta Electoral Central de 26 de mayo de 1986 por el que se designa la Comisión de Radio y Televisión a los efectos de las elecciones generales convocadas por Real Decreto 7941/86, de 22 de abril ${ }^{8}$.

- Escrito de queja de un partido político por no estar incluido en la Comisión de Radiotelevisión y propuesta de constitución de una nueva Comisión para los partidos sin representación parlamentaria (Acuerdo de 2 de junio de 1986).

8 Véase $B O E$ núm. 126, de 27 de mayo de 1986. 
La Junta acuerda desestimar la queja y solicitud, por cuanto la citada entidad política carece de representación parlamentaria y la Ley Electoral no permite constituir esta segunda Comisión.

- Consulta de una Junta Electoral Provincial sobre distribución de espacios gratuitos de Radio Nacional de España prevista en el art. 64 de la LOREG (Acuerdo de 2 de junio de 1986).

La Junta acuerda que, dado lo dispuesto en el art. 62 de la Ley Electoral, el cual se remite al art. 64.1. a), que se remite, a su vez, a las letras b) y c) del mismo art. 64.1, debe entenderse que los votos a tener en cuenta son los obtenidos en el ámbito de difusión, o, en su caso, de programación de los medios.

- Consulta sobre si los funcionarios civiles del Estado proclamados como candidatos tienen derecho a permiso retribuido en la campaña electoral cuando forman parte de candidaturas al Congreso y Senado (Acuerdo de 2 de junio de 1986).

La Junta acuerda que debe entenderse que tienen los derechos reconocidos en la Orden Ministerial de 6 de noviembre de 1985 en relación con el artículo 30.2 de la Ley 30/1984, de 2 de agosto 9.

- Consulta de un medio de comunicación social sobre el modo de interpretación del día de reflexión en determinados programas del medio (Acuerdo de 2 de junio de 1986).

La Junta acuerda comunicar al medio de comunicación social que efectúa la consulta que podrá difundir información objetiva que no entrañe propaganda electoral.

- Reclamación de un partido político contra acuerdo de la Junta Electoral Central por el que se designa la Comisión de Radiotelevisión (Resolución de 2 de junio de 1986).

La Junta acuerda desestimar la reclamación por cuanto en la citada Comisión están representadas todas las entidades políticas que ostentan tal derecho con arreglo a la Ley Electoral.

- Recurso de un partido político contra acuerdo de una Junta Electoral Provincial sobre distribución de espacios gratuitos de propaganda electoral (Acuerdo de 9 de junio de 1986).

La Junta acuerda desestimar el recurso por cuanto el citado par-

9 Orden de 6 de noviembre de 1985, por la que se regula la concesión de permisos a los funcionarios que se presenten como candidatos a las elecciones (BOE número 267 , de 7 de noviembre de 1985). 
tido político no se presenta en el 75 por 100 de las provincias que integran la Comunidad Autónoma.

- Recurso de un partido político sin representación parlamentaria contra acuerdo de una Junta Electoral Provincial de adjudicación de espacios gratuitos en medios de comunicación (Resolución de 9 de junio de 1986).

La Junta acuerda desestimar el recurso por cuanto la distribución acordada por la Junta Provincial respeta los criterios de proporcionalidad establecidos en la Ley Electoral.

- Recurso de algunos partidos políticos con representación parlamentaria contra acuerdo de distribución de espacios adoptado por la Junta Electoral Central en su reunión de 2 de junio de 1986 (Resolución de 9 de junio de 1986).

La Junta acuerda desestimar los recursos, por cuanto el artículo 64.3 de la Ley Electoral no contempla el supuesto de entidades politicas que no hayan obtenido el 20 por 100 de los sufragios emitidos en una Comunidad Autónoma ${ }^{10}$.

- Recurso de una coalición electoral contra acuerdo de una JEP sobre asignación de espacios gratuitos a un partido político que en las anteriores elecciones obtuvo representación parlamentaria formando parte de una coalición electoral (Resolución de 9 de junio de 1986).

La Junta acuerda desestimar el recurso pues, según tiene reiteradamente acordado la JEC, han de reconocerse al citado partido político los escaños y votos obtenidos por el mismo en las elecciones de octubre de 1982 formando parte de una coalición electoral.

- Recursos de varios partidos contra acuerdo de la Junta Electoral Central de distribución de espacios gratuitos de propaganda electoral (Resolución de 9 de junio de 1986).

La Junta acuerda desestimar el recurso, por cuanto el acuerdo de distribución, conforme a propuesta formulada por la Comisión de Radiote-

10 El art. 64.3 de la LOREG 5/85, de 19 de junio, dice lo siguiente: «Los partidos, asociaciones, federaciones o coaliciones que no cumplan el requisito de presentación de candidaturas establecido en el apartado anterior, tienen, sin embargo, derecho a diez minutos de emisión en la programación general de los medios nacionales si hubieran obtenido en las anteriores elecciones equivalentes el 20 por 100 de los votos emitidos en el ámbito de una Comunidad Autónoma en condiciones horarias similares a las que se acuerden para las emisiones de los partidos, federaciones y coaliciones a que se refiere el apartado 1.c) de este artículo. En tal caso la emisión se circunscribirá al ámbito territorial de dicha Comunidad. Este derecho no es acumulable al que prevé el apartado anterior. 
levisión, respeta los criterios de proporcionalidad y preferencias establecidas en la Ley Electoral.

- Solicitud de un partido político de emisiones gratuitas de propaganda electoral en el ámbito territorial de una Comunidad Autónoma (Resolución de 9 de junio de 1986).

La Junta acuerda desestimar la reclamación por cuanto la citada entidad política no cumple el requisito legal de presentarse en el 75 por 100 de las circunscripciones comprendidas en el ámbito de difusión del medio.

- Reclamación de un partido político por la negativa de los medios de comunicación de titularidad pública a facilitar medios técnicos para grabación de espacios gratuitos de campaña electoral (Resolución de 9 de junio de 1986).

La Junta acuerda desestimar la reclamación por cuanto TVE y RNE no están obligadas a facilitar medios técnicos para grabación de espacios gratuitos, sin perjuicio del derecho de las entidades políticas correspondientes a emitir en directo sus espacios.

- Recursos de varios partidos políticos contra acuerdos de algunas Juntas Electorales Provinciales de distribución de espacios gratuitos de propaganda electoral (Resoluciones de 9 de junio de 1986).

La Junta acuerda desestimar los recursos por cuanto el acuerdo de la Junta Provincial respeta el criterio de proporcionalidad establecido en la Ley Electoral.

- Recurso de un partido político contra acuerdo de una JEP sobre distribución de espacios gratuitos de campaña electoral (Resolución de 9 de junio de 1986).

La Junta acuerda estimar el recurso y reconocer el derecho del partido político recurrente a 20 minutos de espacio gratuito en las emisoras de radio de titularidad pública de la provincia.

- Recurso de un partido político contra acuerdo de una JEP sobre distribución de espacios gratuitos de campaña electoral en TVE (Resolución de 9 junio 86).

La Junta acuerda estimar el recurso y reconocer al partido recurrente el derecho a 20 minutos de espacios gratuitos por estar dicho partido, a los efectos de la programación cuya distribución corresponde a la Provincial de Zaragoza, comprendido en el art. 64.1. b) de la Ley Electoral. 
- Recursos de varios partidos políticos contra acuerdos de Juntas Electorales Provinciales sobre distribución de espacios gratuitos de propaganda electoral (Resoluciones de 9 de junio de 1986).

La Junta acuerda desestimar los recursos por cuanto el citado partido no se presenta en el 75 por 100 de las circunscripciones del ámbito de difusión del medio.

- Consulta sobre si un partido político que no ha presentado candidatura a las elecciones puede o no realizar actos de propaganda electoral y pedir la abstención de los electores (Acuerdo de 18 de junio de 1986).

Las entidades políticas no concurrentes a las elecciones no pueden realizar actos de campaña electoral pero sí ejercitar la libertad de expresión amparada por el art. 20 de la Constitución.

- Recurso de un partido político contra acuerdo de la Junta Electoral Provincial que declara no haber lugar a imponer sanción por colocación de vallas pidiendo el voto el día antes del inicio de la campaña (Resolución de 18 de junio de 1986).

La Junta acuerda desestimar el recurso por cuanto:

1. Está acreditado en el expediente que la colocación de vallas se produjo por un error de la empresa publicitaria, sin intención dolosa por parte de ésta ni de la entidad política a que se refiere la valla.

2. La valla estuvo expuesta poco más de treinta minutos, pues antes de que la Junta iniciara actuación ninguna y una vez advertido el error, el propio partido político al que se refiere la valla advirtió a la empresa que la cubriera y ocultara hasta el inicio legal de la campaña.

- Recurso de un partido político contra acuerdo de la Junta Electoral Provincial sobre orden de emisión de espacios gratuitos de propaganda electoral (Resolución de 18 de junio de 1986).

La Junta acuerda la desestimación del recurso, de conformidad con el informe de la Provincial de Valladolid, del que se desprende que el acuerdo recurrido respeta las preferencias establecidas en el art. 67 de la Ley Electoral.

- Recurso de un partido político contra acuerdo de la Junta Electoral Provincial de distribución de espacios gratuitos (Resolución de 18 de junio de 1986). 
La Junta acuerda estimar el recurso de Coalición Popular por cuanto, no habiendo sido impugnada en su día la asignación de espacios a favor de dicha entidad política acordada por la Junta Provincial de Zaragoza, el acuerdo correspondiente es un acto declaratorio de derechos que había llegado a adquirir firmeza sin que quepa la revisión de oficio del mismo.

- Consulta de un partido político sobre acto de campaña electoral seguido de fiesta musical (Acuerdo de 18 de junio de 1986).

La Junta acuerda comunicar al partido político que efectúa la consulta que, a partir de las 0 horas del día 21 puede celebrar la fiesta musical sin realizar actos de propaganda electoral ${ }^{11}$.

- Queja de un partido político por emisión de propaganda el día de reflexión por un medio radiofónico (Resolución de 22 de septiembre de 1986).

Vistas las alegaciones formuladas por el medio radiofónico, la Junta acuerda que no ha lugar a instruir expediente ninguno, puesto que la información emitida el día de reflexión no contenía petición de voto y se limitaba, además, a informar acerca de actividades llevadas a cabo en los días anteriores.

\section{Derecho de rectificación}

- Escrito de una asociación sindical en el que se manifiesta que es falso que dicha organización sea integrante de una coalición electoral como pretendió demostrarse en un programa de propaganda electoral en Televisión (Acuerdo de 18 de junio de 1986).

La Junta acuerda que la reclamación formulada debe plantearse con sujeción a la Ley Orgánica $2 / 1984$, de 23 de marzo, ante las entidades y por las vías establecidas en la citada ley con las especialidades prevenidas en el art. 68 de la Ley Electoral.

- Escrito de una entidad política en el que pretende ejercer el derecho de rectificación por el tratamiento de que ha sido objeto en TVE (Acuerdo de 18 de junio de 1986).

La Junta acuerda que la reclamación formulada debe plantearse con sujeción a la Ley Orgánica $2 / 1984$, de 23 de marzo, ante las entidades y por las vías establecidas en la citada Ley con las especialidades prevenidas en el art. 68 de la Ley Electoral.

11 El día 21 de junio es el día de reflexión (Art. 51.3 de la LOREG). 
- Reclamación sobre rectificación de informaciones emitidas por TVE (Acuerdo 20 de junio de 1986).

La Junta acuerda reiterar que las formas y vías del ejercicio del derecho de rectificación son las previstas en la Ley Orgánica 2/1984, de 23 de marzo, con las especialidades establecidas en el art. 68 de la Ley Electoral, de las cuales no se deriva atribución de competencias en la materia a la Junta Electoral Central.

- Recurso de un partido político contra acuerdo de la JEP relativo a la solicitud del derecho de rectificación por información de los servicios de RTVE (Resolución de 22 de septiembre de 1986).

La Junta acuerda desestimar el recurso por cuanto el derecho de rectificación ha de ejercitarse conforme a lo dispuesto en la Ley Orgánica $2 / 1984$, de 23 de marzo, con las especialidades contempladas en el art. 68 de la Ley Electoral.

\section{Encuestas electorales}

- Consulta sobre posibilidad de difusión de sondeos de resultados electorales el día 22 de junio (Acuerdo de 18 de junio de 1986).

La Junta acuerda:

1. Que no es legalmente posible preguntar a los electores sobre el sentido de su voto dentro de los colegios electorales y en sus inmediaciones.

2. Que los resultados de sondeos de voto o de escrutinio ya realizados en las Mesas electorales pueden hacerse públicos a partir de las 20 horas del día de las elecciones.

Se acuerda asimismo comunicar el punto $1 .^{\circ}$ mediante circular a todas las Juntas Provinciales y difundir mediante nota de prensa el punto $2 .^{\circ}$, el cual será igualmente comunicado a Radio Nacional de España en Cataluña, que formula también consulta sobre el particular.

- Solicitud de interpretación y aclaración del acuerdo de la Junta Electoral Central relativo a la realización de sondeos electorales dentro de los colegios electorales y en sus inmediaciones (Acuerdo de 20 de junio de 1986).

La Junta acuerda reiterar el acuerdo adoptado el día 18 de los corrientes, aclarando que por inmediaciones de los colegios debe enten- 
derse los espacios físicos donde se encuentren personas esperando para ejercer el derecho de sufragio.

- Reclamación de varias entidades políticas por realización de sondeo electoral por una emisora de radio el día de reflexión (Acuerdo de 22 de septiembre de 1986).

La Junta acuerda que no ha lugar a la instrucción de expediente, pues, vistas las alegaciones formuladas por la emisora de radio, la información divulgada por la misma no era un sondeo electoral de intención de voto.

\section{Papeletas y sobres electorales}

- Consulta de diversas Juntas Provinciales y entidades políticas sobre posibilidad de impresión bilingüe de los sobres y papeletas de votación (Acuerdo de 12 de mayo de 1986).

1. Reconocer el derecho a imprimir papeletas y sobres en las distintas lenguas oficiales en cada una de las Comunidades Autónomas que tengan reconocida una lengua oficial además del castellano, pero sin que en ningún caso puedan imprimirse papeletas bilingües, puesto que el Real Decreto 1732/1985, de 24 de septiembre, dispone expresamente en su Anexo 3 que tanto las papeletas para el Congreso como las del Senado contendrán la impresión en una sola cara.

2. En todo caso, los nombres y apellidos de los candidatos deberán figurar en las papeletas en la misma forma e idioma en que figuran en la presentación y proclamación de candidaturas.

- Consulta de diversas Juntas Provinciales sobre impresión bilingüe de sobres y papeletas (Acuerdo de 19 de mayo de 1986).

La Junta acuerda mantener su acuerdo de 12 de los corrientes, así como incluir en el sobre para el voto por correo instrucciones en castellano dirigidas a los electores.

- Consulta sobre momento en que debe realizarse el sorteo previsto en el art. 172. 3. c) a efectos de impresión de las papeletas para el Senado (Acuerdo de 19 de mayo de 1986).

La Junta acuerda que debe realizarse una vez que adquiera firmeza la proclamación de candidaturas. 
- Recurso de un partido político navarro contra acuerdo de la Junta Electoral Provincial sobre impresión de papeletas (Resolución de 16 de mayo de 1986).

La Junta acuerda desestimar el recurso, por cuanto el art. $9 .^{\circ} \mathrm{del}$ Amejoramiento del Fuero de Navarra establece en su apartado 2 que se determinarán por Ley Foral las zonas vascoparlantes de Navarra en las que el vascuence tendrá también, además del castellano, carácter de lengua oficial, sin que tal determinación haya sido llevada aún a cabo, careciendo la Junta de competencia para acordarla.

- Recurso de un partido político catalán contra acuerdo de la Junta Electoral Provincial que deniega solicitud de impresión de papeletas en lengua catalana (Resolución 26 de mayo de 1986).

La Junta acuerda estimar el recurso y declarar el derecho a imprimir papeletas en lengua catalana no bilingües.

- Recurso de un partido político gallego contra acuerdo de la Junta Electoral Provincial sobre impresión de papeletas en gallego (Resolución 26 de mayo de 1986).

La Junta acuerda estimar el recurso y declarar el derecho a imprimir papeletas en idioma gallego no bilingües.

- Consulta sobre si las papeletas para el Senado impresas por los partidos y candidaturas pueden llevar impresa la señal de identificación del voto (Acuerdo de 26 de mayo de 1986).

La Junta acuerda que las papeletas para el Senado impresas por las candidaturas pueden llevar impresa la identificación del voto del elector, si bien tales papeletas no podrán ofrecerse en los colegios electorales el día de la votación, pero sí podrán ser utilizadas por los electores para ejercer el derecho de sufragio; se acuerda enviar circular en este sentido a todas las Juntas Provinciales.

- Consulta sobre si las candidaturas tienen derecho a solicitar un número de papeletas a las Juntas Provinciales (Acuerdo de 26 de mayo de 1986).

La Junta acuerda que ningún precepto legal reconoce tal derecho a los partidos y candidaturas, sino que la Administración sólo está obligada (art. 70. 2) a asegurar la efectiva disponibilidad de papeletas en los colegios electorales y a efectos del voto por correo.

- Consulta sobre situación de las candidaturas en las papeletas para el Senado (Acuerdo de 26 de mayo de 1986).

La Junta acuerda que el orden en que deben figurar las candidaturas es el resultante del sorteo previsto en la Ley. 
- Consulta sobre diferencia del color de los sobres respecto del modelo oficial (Acuerdo de 2 de junio de 1986).

La Junta acuerda que, dada la similitud de tonalidad y las dificultades materiales para que el color sea idéntico al modelo, no existe inconveniente en admitir la validez de los sobres, tal como en otras ocasiones ha acordado la anterior Junta Electoral Central.

- Escrito de un partido político en el que se expone que el Gobierno Civil no les va a proporcionar papeletas (Acuerdo de 2 de junio de 1986).

La Junta acuerda comunicar a la entidad política que efectúa la consulta que el Gobierno Civil, con independencia de lo relativo al voto por correo, sólo está obligado a suministrar papeletas de todas las candidaturas en los Colegios electorales a disposición de los electores.

- Recurso interpuesto por una entidad política asturiana por denegación del uso del bable en el ejercicio del voto y en la información electoral (Resolución de 2 de junio de 1986).

La Junta acuerda desestimar el recurso, por cuanto, con arreglo al Estatuto de Autonomía, el bable no es lengua oficial en la Comunidad Autónoma del Principado de Asturias.

- Consulta de una JEP sobre validez de papeletas al Senado confeccionadas en color similar al modelo (Acuerdo de 9 de junio de 1986).

La Junta acuerda admitir la validez de tales papeletas dada la ligera diferencia de tonalidad con el modelo oficial.

- Recurso de una entidad política contra acuerdo de una JEP sobre confección de papeletas (Resolución 18 de junio de 1986).

La Junta acuerda que, sin perjuicio de la validez de las papeletas hasta ahora impresas y que hayan podido ser remitidas a los efectos del voto por correo, las que se impriman en lo sucesivo deberán contener la mención de la entidad política a la que pertenece cada candidato.

- Recurso de un partido político contra acuerdo de una JEP sobre invalidación de papeletas para el Senado que llevan impreso el signo acreditativo del voto (Resolución de 18 de junio de 1986).

La Junta acuerda estimar el recurso y comunicar a la Provincial que deberá dar cumplimiento a lo acordado por esta Junta Electoral Central en el sentido de que las papeletas para el Senado pueden llevar impresa la identificación del voto del elector, si bien tales papeletas no podrán 
ofrecerse en los colegios electorales el día de la votación, pero sí podrán ser utilizadas por los electores para ejercer el derecho de sufragio.

- Recurso de un partido político contra acuerdo de una JEP sobre validez de papeletas al Senado (Resolución de 20 de junio de 1986).

La Junta acuerda estimar el recurso y declarar la validez de las papeletas a las que el mismo se refiere por razón de la necesidad, dado el momento en que nos encontramos del proceso electoral, de amparar la buena fe del electorado que pueda acudir a ejercitar su derecho de sufragio con las papeletas a que se refiere el recurso y teniendo en cuenta la imposibilidad de proceder a la impresión y remisión de nuevas papeletas.

\section{Voto por correspondencia}

- Consulta sobre si los Consulados podrían actuar como oficinas de correos a los efectos de la solicitud de la documentación para el voto por correo (Acuerdo de 28 de abril de 1986).

La Junta acuerda que, establecido taxativamente en el art. 72 . b) de la Ley Electoral que la solicitud ha de formularse ante el funcionario de correos, no cabe a la Junta la posibilidad de extender dicha función a servicios o funcionarios distintos ${ }^{12}$.

- Consulta sobre mediación de Embajadas y Consulados en el voto por correo de los españoles que accidentalmente se encuentren en el extranjero (Acuerdo de 2 de junio de 1986).

La Junta acuerda reiterar su acuerdo de 28 de abril del corriente año en el sentido de que, establecido taxativamente en el art. 72. b) de la Ley Electoral que la solicitud ha de formularse ante el funcionario de correos, no cabe a la Junta la posibilidad de extender dicha función a servicios o funcionarios distintos; sin perjuicio de que, en uso de la autorización contenida en la disposición adicional segunda de la Ley Electoral pueda el Gobierno, si lo estima oportuno, habilitar como oficinas de correos a los efectos del art. 72 de la Ley Electoral a todas y cada una de las Oficinas Consulares de España en el extranjero.

- Denuncia de una organización sindical por no poder ejercer el derecho de voto un grupo de españoles destacados en un país extranjero (Acuerdo de 9 de junio de 1986).

La Junta acuerda comunicar al Sindicato que; de conformidad con

12 Acuerdo ratificado por la JEC en su reunión de 19 de mayo de 1986. 
el art. 72 de la Ley Electoral, pueden los interesados solicitar la documentación necesaria para el voto por correo mediante persona debidamente autorizada a través de documento autenticado por el cónsul.

- Consulta sobre posibilidad de acreditar la identidad del elector con el pasaporte, carnet de conducir, etc., en el voto por correspondencia (Acuerdo de 18 de junio de 1986).

La Junta declara la validez de dichos documentos si contienen la fotografía del elector a efectos de solicitar la documentación para el voto por correo.

\section{Apoderados e interventores}

- Solicitud de un partido de autorización por la JEC para ostentar emblemas con el nombre y siglas de su partido por los apoderados o interventores (Acuerdo de 9 de junio de 1986).

La Junta acuerda reiterar el criterio de la anterior Junta Electoral en el sentido de que los interventores y apoderados pueden ostentar emblemas adhesivos con el nombre y siglas del partido o coalición y la palabra «interventor» y «apoderado» a los puros efectos de identificación y no con el fin de realizar actividades de campaña electoral ${ }^{13}$.

- Consulta sobre problemas surgidos por el nombramiento de interventores de Mesas Electorales y necesidad de aportar certificación a su inclusión en el censo electoral. Posibilidad de facilitar a las Juntas Electorales de Zona un ejemplar del Censo electoral (Acuerdo de 9. de junio de 1986).

La Junta acuerda comunicar a la Provincial de Teruel que deberá requerir, a tales efectos, el auxilio de la Delegación Provincial de la Oficina del Censo Electoral, que deberá proporcionarle la información necesaria.

\section{Votación}

- Consulta sobre validez de documentos caducados (DNI, pasaporte o permiso de conducir) para acreditar la identidad del votante (Acuerdo de 9 de junio de 1986).

13 Vid. Acuerdo de JEC de 18 de octubre de 1982, en M. Fraile Clivilles, Manual de legislación electoral. Ed. CEURA. Madrid, 1986, pág. 108. 
La Junta acuerda que debe admitirse la validez de los documentos caducados si permiten la acreditación del votante.

- Consulta sobre posibilidad de votar en un momento posterior a una de las Cámaras a la que no se ha votado anteriormente (Acuerdo de 20 de junio de 1986).

La Junta acuerda que el derecho de sufragio se ejercita una sola vez, pudiendo el elector votar para las dos Cámaras o para una sola de ellas, pero sin que pueda votar en momentos separados en una y otra.

\section{Escrutinio en las Mesas Electorales}

- Consulta sobre posibilidad de que en los impresos de certificación de escrutinio para el Congreso, para el Senado, y de acta de la sesión, figuren ya las candidaturas proclamadas en cada distrito por el orden de su proclamación (Acuerdo de 19 de mayo de 1986).

La Junta acuerda que no hay inconveniente legal en cuanto a la certificación de escrutinio para el Congreso, si bien, en cuanto a la certificación de escrutinio del Senado, la relación de candidatos se imprimirá por el orden que resulte en el sorteo previsto en el art. 72.3 de la Ley Electoral.

- Consulta sobre inclusión de los Jueces de Distrito en el art. 101 de la Ley Electoral (Acuerdo de 19 de mayo de 1986).

La Junta acuerda reiterar su acuerdo anterior sobre interpretación del art. 101 de la Ley Electoral ${ }^{14}$.

- Consulta sobre posibilidad de que la entrega de los sobres de las Mesas electorales por los Jueces se haga ante las Juntas de Zona, trasladándolos los funcionarios de éstas a la Provincial (Acuerdo de 26 de mayo de 1986).

La Junta acuerda que el art. 101.3 establece claramente que cel Juez se desplazará personalmente a la sede de la Junta Electoral que deba realizar el escrutinio", por lo que ha de ser el mismo Juez y no ningún otro funcionario quien personalmente debe entregar los sobres a la Junta Provincial.

- Consulta sobre si cabe que los Jueces de Distrito deleguen en el Juez Decano la recogida de sobres de las Mesas electorales (Acuerdo de 26 de mayo de 1986).

14 Institución de la JEC de 17 de febrero de 1986 publicada en el BOE del día 21. 
La Junta acuerda comunicar a la Provincial de Barcelona que no cabe tal delegación, sino que cada Juzgado ha de hacerse cargo de los sobres correspondientes.

- Consulta de una JEP sobre recurso de un Juez de Distrito al que se había encomendado por la JE de Zona la recogida de sobres el día de la votación (Acuerdo de 2 de junio de 1986).

La Junta acuerda que es competencia de las Juntas de Zona asignar la función prevista en el art. 101 de la Ley Electoral al Juez de Distrito o de Primera Instancia e Instrucción, todos ellos comprendidos en dicho precepto, que estimen más conveniente en orden al mejor servicio de la Administración de Justicia y de la Administración electoral.

- Consulta sobre posibilidad de hacer entrega de la documentación electoral prevista en el art. 101 desplazándose a un Juzgado de Distrito (Acuerdo 18 de junio de 1986).

La Junta acuerda que los Jueces encargados de recibir la documentación de las Mesas deben desplazarse personalmente a la Junta Electoral a cuyo fin el Gobierno Civil deberá proporcionar los medios de locomoción y dietas que exija tal operación.

- Consulta solicitando designación de la autoridad judicial competente para la recepción de la documentación de las Mesas electorales (Acuerdo de 18 de junio de 1986).

La Junta acuerda comunicar a la de León que es la Junta Electoral de Zona la competente para designar al funcionario judicial que haya de realizar la operación aludida.

\section{Escrutinio general}

- Consulta sobre si el escrutinio general al quinto día de la votación ha de hacerse sucesivamente o conjuntamente, para los resultados de las elecciones generales y autonómicas (Acuerdo de 26 de mayo de 1986).

La Junta acuerda que el medio legal para atender a los problemas que se le pueden plantear es el contemplado en el art. 105.6 de la Ley Electoral, que permite que la Junta se divida en dos secciones, operando ambas primero en relación con las elecciones generales y después con las autonómicas, de forma que se pueda hacer más breve la duración del acto de escrutinio general. 
- Consulta sobre prórroga del plazo previsto para la realización del escrutinio general (Acuerdo de 18 de junio de 1986).

La Junta acuerda que el plazo previsto en el art. 107.2 de la Ley Electoral para la realización del escrutinio general es improrrogable.

\section{Gastos y subvenciones electorales}

- Consulta sobre si basta con la apertura de una sola cuenta electoral para todo el territorio (Acuerdo de 5 de mayo de 1986).

La Junta acuerda que no hay inconveniente en que se abra una sola cuenta para las elecciones generales.

- Consulta sobre posible federación de agrupaciones de electores a los efectos de designar administrador general común (Acuerdo de 12 de mayo de 1986).

La Junta acuerda que, dados los términos del art. 122.1 de la Ley Electoral, sólo los partidos, coaliciones o federaciones de partidos que presentan candidaturas en más de una provincia designan administrador general común, mientras que las agrupaciones de electores tienen su ámbito limitado por el correspondiente distrito o circunscripción electoral, sin más excepción que la prevista en el art. 64.4 de la Ley Electoral, relativa a la posibilidad de federación de las agrupaciones de electores a los efectos de participar en la distribución de los espacios gratuitos de campaña electoral en los medios de titularidad pública, a cuyos solos efectos la federación deberá hacerse constar ante la Junta competente para distribución de los espacios, pero sin que sea admisible la federación de agrupaciones de electores a otros efectos.

- Consulta sobre apertura de una cuenta electoral única para todo el territorio nacional y sobre control de intervención por parte del Ministerio de Hacienda (Acuerdo de 26 de mayo de 1986).

La Junta acuerda

a) En cuanto a la primera cuestión, hay que recordar que la Junta Electoral Central acordó en la sesión celebrada el 5 de mayo de 1986 que no hay inconveniente en que se abra una sola cuenta para las elecciones generales.

b) En cuanto a la segunda cuestión, el art. 133 de la Ley Orgánica del Régimen Electoral General preceptúa que la contabilidad detallada y documentada de los ingresos y gastos electo- 
rales de partidos, coaliciones, federaciones y agrupaciones de electores que hubieran recibido subvenciones electorales se presentará ante el Tribunal de cuentas -a quien corresponde la función fiscalizadora de la contabilidad electoral- por los administradores generales de aquellos partidos, federaciones o coaliciones que hubieran concurrido a las elecciones en varias provincias y por los administradores de las candidaturas en los restantes casos.

- Consulta sobre posibilidad de ingresar fondos para gastos electorales después de las elecciones (Acuerdo de 18 de junio de 1986).

La Junta acuerda que no existe prohibición legal expresa en principio, por lo que parece que se permite tal posibilidad.

- Denuncia de una entidad política por los gastos electorales de otra entidad política y solicitud de fiscalización de los mismos por parte de la JEC (Acuerdo de 22 de septiembre de 1986).

Dado que el escrito de referencia no contiene denuncia de hechos concretos, la Junta acuerda no iniciar expediente alguno por cuanto la fiscalización de los gastos debe someterse a la competencia que la Ley Orgánica del Régimen Electoral General reconoce al Tribunal de Cuentas.

- Escrito de un partido político en el que solicita relación de los gastos realizados por todas las entidades políticas que participaron en las elecciones de 22 de junio de 1986 (Acuerdo de 22 de septiembre de 1986).

La Junta acuerda que no ha lugar a la solicitud por carecer el Partido del derecho que reclama.

\section{Proclamación de resultados}

La Junta Electoral Central en la sesión celebrada el día 15 de julio de 1986, de conformidad con lo dispuesto en el art. 108.4 de la Ley Orgánica del Régimen Electoral General acuerda ordenar la publicación en el Boletín Oficial del Estado de los resultados generales y por circunscripciones de las elecciones celebradas el 22 de junio de $1986^{15}$.

15 Vid. BOE núm. 184 de 2 de agosto de 1986 que contiene el resumen de los resultados de las elecciones celebradas el dia 22 de junio de 1986, según los datos que figuran en las actas de escrutinio general remitidas por cada una de las Juntas Electorales Pro- 


\section{ADDENDA}

Instrucciones, Resoluciones y Acuerdos de la JEC en relación a las elecciones al Parlamento de Andalucía convocadas por Decreto del Presidente de la Junta de Andalucía, 73/1986, de 28 de abril y celebradas el 22 de junio de 1986.

- Consulta sobre competencia en orden al control de gastos y subvenciones electorales en las elecciones al Parlamento de Andalucia (Acuerdo de 5 de mayo de 1986).

La Junta acuerda comunicar a la de la Comunidad Autónoma de Andalucía que corresponden a dicha Junta autonómica las competencias en la materia.

- Consulta sobre la Comisión de Radiotelevisión competente para proponer la distribución de espacios gratuitos de campaña electoral en relación con las elecciones al Parlamento de Andalucía (Acuerdo de 5 de mayo de 1986).

La Junta acuerda que la citada competencia corresponde a la Junta Electoral de Andalucía a propuesta de la Comisión de Radiotelevisión constituida bajo su dirección.

- Consulta sobre posibilidad de abrir una sola cuenta electoral para las elecciones generales y las autonómicas de Andalucía (Acuerdo de 5 de mayo de 1986).

La Junta acuerda que deben constituirse cuentas separadas para unas y otras elecciones, dada la distinta competencia en orden al control

vinciales:

- Cuadro I. Resumen general.

- Cuadro II. Relación de votos correspondientes a cada uno de los partidos, federaciones, coaliciones o candidaturas que han obtenido escaños y número de éstos.

- Cuadro III. Relación de votos correspondientes a cada uno de los partidos, federaciones, coaliciones o candidaturas que no han obtenido escaño.

- Relación de Diputados que han obtenido escaño y de la formación política y circunscripción a que pertenecen.

- Relación de Senadores proclamados electos en cada circunscripción, así como de los candidatos que no han obtenido escaño, con indicación de la formación política a la que pertenecen y número de votos obtenidos.

Vid. asimismo BOE núm. 270 de 11 de noviembre de 1986.

Rectificación de errores materiales en el resumen de los resultados de las elecciones al Congreso de los Diputados y al Senado celebradas el día 22 de junio de 1986, según los datos que figuran en las actas de escrutinio general remitidas por cada una de las Juntas Electorales Provinciales, publicado en el BOE del 2 de agosto de 1986. 
de los respectivos gastos electorales y acerca del pago de las subvenciones electorales.

- Consulta sobre necesidad de doble apoderamiento o doble acreditación para Interventores o Apoderados que en un mismo Colegio o Mesa Electoral vayan a actuar como tales en ambos procesos electorales (Acuerdo de 19 de mayo de 1986).

La Junta acuerda que basta una designación común para ambos proceso electorales.

- Consulta sobre posibilidad de ser simultáneamente candidato a las elecciones al Parlamento de Andalucía y suplente en candidatura en elecciones generales (Acuerdo de 19 de mayo de 1986).

La Junta acuerda que es posible legalmente tal simultaneidad, puesto que lo que prohíbe el art. 155.3 de la Ley Electoral es acumular el acta de una Asamblea de una Comunidad Autónoma con la de Diputado al Congreso, pero no ser candidato a una Asamblea de Comunidad Autónoma y al Congreso de los Diputados.

- Consulta sobre si es preciso ejercitar simultáneamente el derecho de sufragio en las elecciones generales y autonómicas o si se puede votar en momentos distintos dentro de la jornada electoral (Acuerdo de 19 de mayo de 1986).

La Junta acuerda que en el mismo momento habrá de ejercitarse el derecho de sufragio en relación con las elecciones generales y autonómicas.

- Consulta sobre si la campaña electoral para el Parlamento de Andalucía, prevista en la Ley para el 6 de junio, se puede ampliar o adelantar al 31 de mayo al coincidir con las elecciones generales (Acuerdo de 26 de mayo de 1986).

La Junta acuerda que la campaña electoral comienza para cada proceso en las fechas señaladas en las disposiciones de aplicación. 